\title{
Bi-allelic alterations in DNA repair genes underpin homologous recombination DNA repair defects in breast cancer
}

Robert W. Mutter ${ }^{1,2 \dagger}$, Nadeem Riaz ${ }^{1 \dagger}$, Charlotte K. Y. Ng ${ }^{3^{*}}$, Rob Delsite ${ }^{1}$, Salvatore Piscuoglio $^{3}$, Marcia Edelweiss ${ }^{3}$, Luciano G. Martelotto ${ }^{3}$, Rita A. Sakr ${ }^{4}$., Tari A. King ${ }^{4}$, Dilip D. Giri ${ }^{3}$, Maria Drobnjak ${ }^{3}$, Edi Brogi ${ }^{3}$, Ranjit Bindra ${ }^{1,5}$, Giana Bernheim ${ }^{1}$, Raymond S. Lim ${ }^{3}$, Pedro Blecua ${ }^{1}$, Alexis Desrichard ${ }^{6}$, Dan Higginson ${ }^{1}$, Russell Towers ${ }^{4}$, Ruomu Jiang $^{7}$, William Lee ${ }^{1}$, Britta Weigelt ${ }^{3}$, Jorge S. Reis-Filho ${ }^{3,6}$, Simon N. Powell ${ }^{1,{ }^{*}}$

\author{
Affiliations: \\ York, NY \\ Center, New York, NY \\ ${ }^{\dagger}$ Contributed equally \\ * Correspondence to: \\ Simon N. Powell, M.D., Ph.D. \\ Chair, Radiation Oncology \\ Memorial Sloan Kettering Cancer Center \\ Department of Radiation Oncology \\ 1275 York Avenue, Box 22 \\ New York, NY 10065 \\ Email: powells@mkscc.org
}

${ }^{1}$ Department of Radiation Oncology, Memorial Sloan Kettering Cancer Center, New

${ }^{2}$ Department of Radiation Oncology, Mayo Clinic, Rochester, MN

${ }^{3}$ Department of Pathology, Memorial Sloan Kettering Cancer Center, New York, NY

${ }^{4}$ Department of Surgery, Memorial Sloan Kettering Cancer Center, New York, NY

${ }^{5}$ Department of Radiation Oncology, Yale, New Haven, CT

${ }^{6}$ Human Oncology and Pathogenesis Program, Memorial Sloan Kettering Cancer

${ }^{7}$ Department of Systems Biology, Harvard Medical School, Boston, MA

Running Title: Homologous recombination defective breast cancers

Conflict of Interest statement: The authors have declared that no conflict of interest existis. the author manuscript accepted for publication and has undergone full peer review but has not been through the copyediting, typesetting, pagination and proofreading process, which may lead to differences between this version and the Version of Record. Please cite this article as doi: $10.1002 /$ path.4890

This article is protected by copyright. All rights reserved. 


\section{Abstract:}

Homologous recombination (HR) DNA repair deficient (HRD) breast cancers have been shown to be sensitive to DNA repair targeted therapies. Burgeoning evidence suggests that sporadic breast cancers, lacking germline BRCA1/BRCA2 mutations, may also be HRD. We developed a functional ex vivo RAD51-based test to identify HRD primary breast cancers. An integrated approach examining methylation, gene expression and whole-exome sequencing was employed to ascertain the etiology of HRD. Functional HRD breast cancers displayed genomic features of lack of competent HR, including large-scale state transitions and specific mutational signatures. Somatic and/or germline genetic alterations resulting in bi-allelic loss-of-function of HR genes underpinned functional HRD in $89 \%$ of cases, and were observed in only one of the $15 \mathrm{HR}$-proficient samples tested. These findings indicate the importance of a comprehensive genetic assessment of bi-allelic alterations in the HR pathway to deliver a precision medicinebased approach to select patients for therapies targeting tumor-specific DNA repair defects.

Keywords: BRCAness, homologous recombination deficient, RAD51, DNA repair, mutation

This article is protected by copyright. All rights reserved. 


\section{Introduction:}

Homologous recombination (HR) plays a critical role in the repair of double strand breaks (DSBs), replication-associated DNA damage, and inter-strand crosslinks.[1] Germline mutations affecting specific known HR repair genes result in an increased risk of breast cancer development.[2] For example, BRCA1 and BRCA2 germline mutations are present in approximately $5-7 \%$ of all breast cancers.[3] The protein products encoded by the BRCA1/2 genes are essential members of the HR pathway, assisting in the maintenance of genomic integrity. In the absence of HR, DSBs are repaired by more error-prone mechanisms, such as non-homologous end joining, leading to genomic instability and tumorigenesis. Cells with homologous recombination deficiency (HRD) have been shown to be exquisitely sensitive to platinum-based chemotherapy and poly(ADP-ribose) polymerase (PARP) inhibitors, which produce replication-associated DSBs. Therefore, HRD has been targeted in cancers with the aim of exploiting a tumorspecific deficiency in DNA repair.[4] This "synthetic lethal" approach has recently led to the approval of PARP inhibitors for BRCA1/2-associated ovarian cancers and the investigation of cisplatin and PARP inhibitors in BRCA1/2-associated breast cancers. [5-

8]

There are burgeoning data suggesting that HRD is likely present in a subset of nonBRCA1/BRCA2-mutant sporadic breast cancers.[9] The etiology of HRD in sporadic breast cancer, however, still remains unclear and the identification of these tumors in the clinic remains challenging. HRD in cancer results in a distinctive pattern of genomic instability due to the deficiency in error-free DNA double strand break repair by HR.[10- 
12] Therefore, biomarkers based on genomic landscape 'scars' or 'footprints' (i.e. patterns of somatic genetic alterations assessed by large-scale state transitions (LST), telomeric regions with allelic imbalance $(\mathrm{NtAl})$, or large segments with loss-ofheterozygosity (Myriad LOH/HRD)), which are commonly seen in BRCA1/2 associated breast cancer due to HRD, have been proposed for the identification of sporadic breast cancers with HRD.[13-16] Although these genomic landscape biomarkers correlate well with $B R C A 1 / 2$ germline mutations, their clinical utility in breast cancer has been limited because of their modest positive-predictive value.[17,18]

The DNA recombinase RAD51 forms a focus at DNA damage sites, which become visible using immunofluorescence microscopy, and mark sites of ongoing DNA repair. The recruitment of RAD51 to single strand DNA, catalyzes strand invasion, and is a crucial step in HR that is dependent on the functional integrity of the entire pathway.[1] Hence, the assessment of RAD51 has been proposed as a surrogate for competent HR DNA repair; however, previous approaches require patients to receive systemic cytotoxic therapy within a short period prior to tumor biopsy for biomarker assessment.[19] To address the unmet need of a test that accurately assesses the functional status of HR at the time of diagnosis, we utilized a functional RAD51 assay to measure HR in prospectively accrued human breast cancer specimens. After benchmarking this assay on the basis of the clinic-pathologic and genomics features of the tumors, we sought to define the underlying etiology of HRD in breast cancers employing a multi-faceted genomic approach (Figure 1).[20] 


\section{MATERIALS AND METHODS}

\section{Patients}

We obtained fresh and flash frozen tumor specimens from 56 breast cancer patients diagnosed between August 2010 and April 2012. (Supplementary Table S1). This study was approved by the Institutional Review Board, and informed consent was obtained from all patients prior to enrollment. Details of inclusion/ exclusion criteria are described in the Supplementary Materials and Methods.

\section{Ex vivo treatment and DNA repair protein foci assay of homologous recombination}

Following excision, and without delay, the lumpectomy or mastectomy specimen was assessed grossly by a breast cancer pathologist and a fraction of the tumor was set aside in chilled complete cell culture medium. A cell suspension was created and divided equally, with one half being irradiated with $10 \mathrm{~Gy}$, while the other half was mocktreated (i.e. not irradiated). The samples were then incubated in for $4 \mathrm{~h}$, after which they were mounted on glass slides. Cell nuclei were analyzed for subnuclear foci formation of RAD51 in both the irradiated and mock-treated (i.e. non-irradiated) states as a functional readout of $\mathrm{HR}$. IR-induced $\mathrm{\gamma H} 2 \mathrm{AX}$ foci formation was analyzed to assess the quality of the preparation and cell viability at the time of DNA damage and fixation, in addition to being used as a surrogate for DNA Damage. BRCA1 foci formation was also assessed to facilitate the localization of potential defects in the HR pathway. At least 200 nuclei were counted for both the irradiated and non-irradiated conditions of a 
given case. A nucleus was scored as positive if it contained $>5$ foci, as described previously.[20]

\section{Immunohistochemistry (IHC)}

$\mathrm{IHC}$ analysis was performed on the matching formalin-fixed, paraffin-embedded tissue sections of the breast cancers included in this study using antibodies against PCNA and

Ki67 using standard procedures and validated controls (Supplementary Materials and Methods).

\section{Nucleic acid extractions}

DNA and RNA were extracted from representative flash frozen tumor sections using the DNeasy Blood \& Tissue kit (Qiagen) and TRIzol (Life Technologies), respectively (Supplementary Materials and Methods).

\section{BRCA1 promoter methylation}

Genomic DNA (100 $\mathrm{ng}$ ) from each breast cancer was bisulfite-converted using the EpiTect Plus Bisulfite Kit (Qiagen). Purified converted DNA was subjected to methylation-specific PCR (MSPCR) using the EpiTect MSP Kit (Qiagen) as descried in Supplementary Materials and Methods).

\section{Whole-exome sequencing and copy number analysis}

DNA extracted from snap-frozen tumors and germline were subjected to whole exome capture using the SureSelect Human All Exon v4 (Agilent) capture system and to 
massively parallel sequencing on an Illumina HiSeq 2000. Whole-exome sequencing analysis was performed as described in Weinreb et al. with modifications (Supplementary Materials and Methods). Prior to analysis, two authors (S.N.P, N.R.) curated a list of 95 genes that are direct or indirect effectors or regulators of HR using the literature and author experience.[21,22] Comparison of the number of cases with the complete loss of both alleles of at least one HR gene according to functional RAD51 foci formation status was performed using Fisher's exact test.

\section{Analysis of genomic 'scars'}

Large-Scale state transitions (LST), telomeric regions with allelic imbalance (NtAl), or large segments with loss of heterozygosity (Myriad LOH/HRD) scores were derived from whole-exome sequencing data. Derivation of these scores from allele specific segmented data were determined following methods outlined in the initial publications and described in detail in the Supplementary Materials and Methods.[13-15]

\section{Analysis of mutational signatures}

Mutational signatures were defined using whole-exome sequencing data as described in Supplementary Materials and Methods.

This article is protected by copyright. All rights reserved. 


\section{$\underline{\text { Results: }}$}

\section{Functional Analysis of RAD51 Foci Formation to Define HR DNA Repair Defects}

HRD was evaluated using a quantification of RAD51 foci in cancer cells subjected to ex vivo ionizing radiation (IR), which has previously been shown to be a robust readout of the integrity of HR in vitro.[20] We obtained tumor specimens from 56 consecutive patients with breast cancers prospectively (Table 1). In brief, immediately after surgical resection, we generated single cell suspensions from each tumor. For each patient, half of these suspensions were irradiated with $10 \mathrm{~Gy}$. Cell nuclei were analyzed for the formation of RAD51 foci in both irradiated and un-irradiated cells. To ascertain that RAD51 deficiency was not due to cellular quiescence, we used immunohistochemical analysis of the proliferation marker Ki67 (Supplementary Figure S1a-b). As HR is limited to the S/G2 phases of the cell cycle and an absence of RAD51 induction denotes HRD, we only considered cases for further analysis if they showed sufficient levels of Ki67 staining (proficient $>5 \%$; deficient $>20 \%$; Supplementary Figure S2). Forty-nine tumors had sufficient levels of proliferation, as defined by Ki67, for subsequent analysis. By assessing the induction of RAD51 foci formation in irradiated vs un-irradiated cells, we observed that $78 \%$ (38/49) of the tumors displayed a significant increase in RAD51 foci following IR (Figure 2a,c,e), a phenotype we classified as "RAD51 proficient". In addition, $22 \%$ (11/49) of tumors lacked a significant increase in RAD51 foci following IR (Figure 2b,d,e). We classified these tumors as "RAD51 deficient".

The relative fold-increase in RAD51 recruitment following IR displayed a clear bi-modal distribution in the breast cancers analyzed (Figure 2e). The 38 RAD51 proficient tumors 
also displayed BRCA1 foci induction following IR. In 7 of the 11 tumors classified as RAD51 deficient, there was also no induction of BRCA1, whereas 4 RAD51 deficient tumors exhibited a 2- to 5-fold increase in BRCA1 foci formation following IR. Notwithstanding these 4 cases, induction of RAD51 foci was linearly related to induction of BRCA1 foci $(r=0.91, p<0.001$, Supplementary Figure S1c). RAD51 deficiency (i.e. functional HRD) was observed in all clinical subtypes. A numerically but not statistically significant higher prevalence of functional HRD, however, was documented in triplenegative breast cancers (42\%, Figure 2f). No association between HRD and other clinico-pathologic features was observed (Table 2).

\section{Relationship between functional HR assays and genomic 'scars'}

We next sought to define whether breast cancers with functional HRD, as defined by the ex vivo RAD51 assay, would display genomic 'scars' or mutational signatures consistent with HRD.[13-16,23,24] A subset of 24 tumors from which sufficient DNA was available, including nine RAD51-defective tumors and 15 RAD51-foci-positive controls (Supplementary Tables S1 and S2), was subjected to whole-exome sequencing. Consistent with our hypothesis, tumors with functional HRD (i.e. RAD51-deficient) had significantly higher number of $B R C A 1 / 2$-like genomic 'scars' than HR-proficient breast cancers. The LST, ntAI, LOH/HRD scores, and the number of insertions and deletions (indels) were significantly higher in tumors with functional HRD (Wilcoxon rank-sum test $p=0.002, p=0.009, p=0.048$ and $p=0.044$, respectively; Figure $3 a-c)$. The positive predictive value, negative predictive value, and accuracy of LST using a cut-off of 15 (as per initial report [13]) to determine RAD51 functional status were $59 \%, 90 \%$, and $82 \%$, 
respectively. In addition, using a validated approach to classify cancers into the 21 mutational signatures that shape the genomes of human cancers [23], we observed that the $B R C A 1 / 2$ mutational signature (signature 3$)$ was present in $4 / 9(44 \%)$ RAD51deficient breast cancers but in none of the 15 RAD51-proficient cases $(p=0.02$, Fisher's exact test, Figure 5), suggesting that this signature may only identify a subset of breast cancers with HRD (i.e. three of five tumors with BRCA1 and BRCA2 pathogenic mutations did not display the $B R C A 1 / 2$ mutational signature). Taken together, we demonstrate that HRD breast cancers as defined by a functional RAD51 foci assay display the expected cardinal genomic features of breast cancers lacking competent HR DNA repair (e.g. those of BRCA1/2 hereditary breast cancers).

\section{Integrated Genetic Analysis HR Deficient and Proficient Tumors}

We next sought to identify the etiology of functional HRD. We measured mRNA levels of a panel of HR genes, including BRCA1, BRCA2, RAD51, RAP80 and FAM175, in HRD and HR DNA repair competent cases using NanoString technology (Figure 4). The expression levels of the HR genes were found not to be associated with HRD. Similarly, $B R C A 1$ gene promoter methylation was also not associated with functional HRD status in tumors analyzed although BRCA1 gene promoter methylation was detected in only two cases.

Given that alterations in multiple HR genes in addition to BRCA1/2 have been associated with either predisposition to breast or ovarian cancer or response to DNA damaging chemotherapy,[2,25] we posited that functional HRD may be underpinned by 
genetic alterations that target distinct components of the HR pathway in sporadic breast cancers. Importantly, there is evidence to suggest that for most HR genes, bi-allelic loss is essential for cancer cells to be HR DNA repair deficient.[9,26-28] Whole-exome sequencing analysis revealed that bi-allelic germ-line and/or somatic genetic alterations affecting 95 previously-reported HR DNA repair pathway genes (Supplementary Table S3) accounted for the functional HRD observed in 8/9 (89\%) cases analyzed (Figure 5 and Supplementary Tables S4 - S6).[21,22] For instance, 4/9 patients with functional HRD harbored alterations in BRCA2 (Figure 5), all of which likely resulted in a complete loss of BRCA2 (germline frameshift mutation with LOH (Case SP15), somatic frameshift mutation with LOH (Case SP28), a somatic exon 3 duplication with LOH (Case SP5), and a somatic homozygous deletion (Case SP17). Consistent with its role upstream of BRCA2 in the HR pathway, IR-induced BRCA1 recruitment into DNA repair foci was preserved in these four tumors. Four additional HRD cases had bi-allelic alterations of bona fide HR genes, including one case with a CHEK2 somatic homozygous deletion (Case SP6). Loss of CHEK2 diminishes RAD51 recruitment to the sites of DNA damage following IR (unpublished observation).[29,30] The two cases with somatic homozygous deletions of either BRCA2 (Case SP17 or CHEK2 (Case SP6) had negligible mRNA expression levels of the corresponding gene (Supplementary Figure S3), providing additional evidence of the functional consequence of the homozygous deletions detected. Two additional HRD cases showed non-synonymous somatic mutations and LOH in FAAP100 (Cases SP16 and SP26), a Fanconi Anemia associated protein. Integrity of the Fanconi anemia pathway is required for RAD51 recruitment and HRD results when this pathway is inactivated.[31] Another case had a mutation and LOH in 
TP53BP1, which may result in a switch from repair of double strand breaks with fidelity by $\mathrm{HR}$, to a reliance on RAD52-mediated mutagenic single-strand annealing.[32] Case SP6, in addition to a CHEK2 homozygous deletion, also harbored a homozygous deletion in BABAM1 (MERIT40 or NBA1), a member of the BRCA1-A complex known to affect BRCA1 and RAD51 recruitment.[33] The only RAD51 foci formation proficient case displaying a bi-allelic inactivation of an HR gene was case SP20. This tumor despite harboring a germline frameshift mutation in BRCA1 coupled with $\mathrm{LOH}$ of the wild-type allele, was found to be proficient for the induction of RAD51 and BRCA1 foci, and did not display an elevated LST score or a BRCA mutational signature. In addition, this case did not display evidence of intra-genic deletions or revertant mutations in the tumor, nor did it have low expression of 53BP1, suggesting there might be additional mechanisms that can restore HR function in BRCA1-mutant breast cancers.[34-36] In total, 8/9 of RAD51-deficient cancers harbored a bi-allelic inactivation of at least one HR gene compared to $1 / 15$ of RAD51-proficient cancers $(p<0.001$, Fisher's exact test), suggesting these eight cases likely had a genetic etiology for functional HRD. The sole case that was RAD51 deficient and did not contain bi-allelic inactivation of an HR DNA repair gene, also failed to induce BRCA1 foci following IR, and did not have evidence of a genomic scaring (LST) or a mutational signature. Further BRCA1 promoter methylation was absent and there was not any obvious aberration gene expression of BRCA1 or other HR genes. This suggests possibly a genetic alteration not surveyed by whole-exome sequencing (e.g. somatic genetic alterations affecting non-protein coding regulatory elements or genetic rearrangements) or an epigenetic alteration may have resulted in HRD in this case. Of note, single-allelic alterations in HR genes occurred in 
12 cases and were associated with RAD51-deficiency, albeit less strongly than bi-allelic inactivation. ( $p=0.01$; Fisher's exact test; Supplementary Figure S4).

The nine cases with bi-allelic inactivation of HR DNA repair genes, including the BRCA1 germline mutated but RAD51-proficient case, were found to have a significant association with higher LST scores ( $p=0.001$, Wilcoxon rank-sum test, Figure $3 d)$. To determine whether the association between bi-allelic inactivation or HR genes and HR deficiency would be generalizable, we performed an analysis of breast cancer samples from The Cancer Genome Atlas (TCGA) study (See Supplementary Materials and Methods).[37] In the TCGA dataset, breast cancers with a bi-allelic genetic alteration in the HR pathway gene panel also displayed significantly higher LST scores than those that did not ( $p<0.001$, Wilcoxon rank-sum test, Supplementary Figure S5).

Taken together, our findings demonstrate that in 8 of 9 breast cancers displaying functional HRD, the lack of competent HR DNA repair was likely caused by bi-allelic genetic inactivation of a bona fide HR-related gene. Although we included TP53BP1 in our gene panel of HR regulators and effectors, a priori, we acknowledge that mutations in this gene may promote $\mathrm{HR}$, especially in a BRCA1 mutant background (which was not the case in any of the tumors analyzed in this study). Further, emerging evidence, suggests that TP53BP1 plays a critical role in supporting the accumulation of RAD51 at IR-induced DNA double strand breaks. Rather than suppressing HR in a BRCA1 wildtype background, loss of 53BP1 may trigger a hyper-resection phenotype, leading to replacement of RAD51 by RAD52 and redirecting repair from HR to more mutagenic 
single-strand annealing.[32] Nevertheless, excluding this case (i.e. only 7 of 9 cases with bona-fide bi-allelic HR genes) does not significantly alter our findings. Bi-allelic alterations were still found to be significantly associated with RAD51 deficiency and correlate with LST $(p<0.001$ and $p<0.01$; Fisher's exact test and Wilcoxon-rank sum test, respectively).

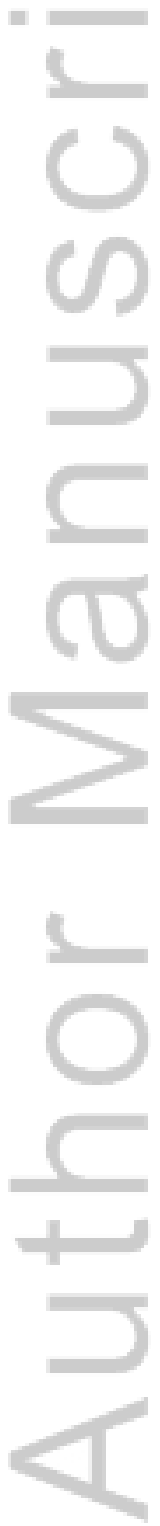

This article is protected by copyright. All rights reserved. 


\section{Discussion}

Here, we developed and validated an ex vivo functional assay for the identification of HRD breast cancers. This assay revealed that over $20 \%$ of the breast cancers analyzed were found to have a functional deficiency in the HR pathway. This RAD51 fociinduction assay is the only HRD classifier to display a bimodal distribution, suggesting that there is a biologically driven categorization of breast cancers by status of the HR pathway. Breast cancers classified as functionally HRD displayed the cardinal genomic features reported to be present in tumors lacking competent HR, including high LST scores and the BRCA mutational signature (i.e. signature 3). Although HRD was most frequently observed in triple-negative breast cancers, this functional deficiency was also present in ER-positive and/ or HER2-positive disease. An integrative genomic analysis of cases with and without HRD revealed that the likeliest etiology for HRD in the vast majority of cases is bi-allelic inactivation of bona fide HR genes, and that BRCA1 gene promoter methylation and transcriptomic changes in HR genes were not associated with functional HRD. These observations demonstrate that HRD is predominantly caused by genetic events during tumorigenesis and tumor evolution, and that this phenomenon likely constitutes a convergent phenotype in breast cancers. [9,38]

Germline variants in HR genes besides $B R C A 1 / B R C A 2$ are associated with breast cancer predisposition, and underlie the importance of assessing the genotype of the entire pathway.[2,39] Genetic alterations affecting HR pathway-related genes have been linked to response to HR-targeted therapies in multiple other cancers. $[25,40,41]$ In ovarian cancer, somatic and germline assessment of a panel of $13 \mathrm{HR}$ genes was 
significantly associated with platinum sensitivity and overall survival in a cohort of 390 ovarian cancer patients.[25] A Phase II trial of a PARP inhibitor in metastatic prostate cancer also identified somatic and/or germline alterations in a panel of DNA repair genes was significantly associated with response, with $88 \%$ of patients who responded to therapy harbored a genetic alteration in an HR DNA repair-related gene.[40] Our results provide direct evidence to support the novel concept that bi-allelic germline and/or somatic alterations in HR genes, rather than the mere presence of a mutation in these genes, lead to phenotypic functional defect in HR and provide a mechanistic basis for these recent clinical observations. Further, we extend the significance of a comprehensive somatic and germline genetic assessment of the HR pathway genes to both the risk and treatment of breast cancer patients.

We were not able to find a clear role for aberrant HR gene expression or BRCA1 promoter methylation in mediating functional HR deficiency in our study. Although, methylation of BRCA1 is enriched in breast cancers compared to normal breast epithelium and leads to reduced BRCA1 expression, whether these changes have phenotypic consequences remains unclear.[42] In our cohort of breast cancer patients, we only identified two cases with BRCA1 promoter methylation, of which, one case was HR proficient and the other was HRD. Hence, we did not find clear evidence that would support the contention that epigenetic alterations in BRCA1 deregulate HR. In other malignancies, such as ovarian cancer, BRCA1 promoter methylation occurs in $10-20 \%$ of cases and is mutually exclusive of BRCA1 mutation.[26] Interestingly, though, epigenetic dysregulation of HR in ovarian cancer does not appear to be linked with 
overall survival or progression free survival after treatment with cisplatin.[43] Ultimately larger cohorts may be required to link epigenetic changes to phenotypic deficiencies in $H R$, i.e., drug response, in vitro assays, or genomic scars.

The only patient with dysfunctional HR who did not have a bi-allelic alteration in a bona fide HR gene, also lacked evidence of a genomic 'scar' or mutational signature consistent with HRD. On the opposite end of the spectrum, we identified one tumor with a bi-allelic BRCA1 mutation without evidence of a functional deficit in HR. This case did not display evidence of intra-genic deletions or reversion mutations in the tumor. Moreover, 53BP1 gene expression was assessed, and levels were not significantly lower than those detected in other samples. Other mechanisms of restoring DNA repair in BRCA1 deficient tumor cells have been reported, such as alterations in RIF1, HELB, PTIP or MAD2L2.[44-47] In addition, this case displayed a frameshift mutation in $B R C A 1$ at the $C$ terminus in the $2^{\text {nd }} B R C T$ domain (GIn1777fs) and also lacked both a high LST score and mutational signature 3. In ovarian cancer, mutations towards the end of the gene have been associated with a worse overall survival (as opposed to mutation in other portions of the gene which are associated with improved survival) suggesting the possibility that this particular mutation may not necessarily result in an HR deficiency.[48]

Consistent with the notion that genomic 'scars' and mutational signatures are present in breast cancers with HRD, here we demonstrate using a functional HRD test that these genomic 'scars' and mutational signatures are present not only in BRCA1/BRCA2 
breast cancers, but also in non-BRCA1/BRCA2 breast cancers displaying functional HRD. It should be noted, however, that the mutational signature of BRCA1 and/ or BRCA2 breast cancers (signature 3 from Alexandrov et al.)[23] seems to identify a more limited subset of HRD breast cancers than the ex vivo RAD51-based functional assessment described here. In addition, genomic 'scar' predictors of HRD only have moderate positive predictive value for functional HRD providing one reason for the modest utility of these assays in clinical trials. $[17,18]$ Using the finding from our clinical data of a strong relationship between functional HRD and bi-allelic alterations in HR genes, we interrogated the TCGA data to identify cases with bi-allelic alterations in DNA repair genes. As anticipated, TCGA cases with bi-allelic alterations had a higher prevalence of genomic scars (i.e. high LST score), providing additional support for our hypothesis.

The results of the functional RAD51 assay described here, in conjunction with other studies[19,49] highlight the need for a biomarker of HR function to select breast cancer patients who may benefit from synthetic lethal approaches targeting HRD. Direct testing of induced RAD51 is challenging to implement as a routine clinical test due to the need for fresh tissue, rapid processing, and specialized assessment.[50] In a translational setting, however, functional assessment of the HR pathway can allow for a more thorough interpretation of genomic alterations measured simultaneously. Bi-allelic inactivation of HR genes was found to identify almost $90 \%$ of cases with a functional HR defect, with only one false positive result. 
This study has important limitations, including the relatively small sample size. However, functional ex vivo testing is difficult to perform in a large-scale setting. We used research versions of LST and other genomic 'scar' methods which may slightly alter the performance characteristics described here. Lastly, one of the genes in our a prior determined panel of HR genes, TP53BP1, is known to regulate pathway choice between HR and NHEJ.[51] In a BRCA1 mutant background, depletion of TP53BP1, rescues an HR defective phenotype. Recent work however, has suggested that in a BRCA1 wild-type setting, TP53BP1 is important for adequate RAD51 induction after IR and that exhaustion of TP53BP1 leads to hyper-resection (and possibly faulty HR).[32] Regardless, the exclusion of this particular case (SP29), does not significantly alter our observation that bi-allelic inactivation of HR DNA repair-related genes is significantly associated with functional HRD and high LST scores.

In conclusion, we identified the genetic basis of HR deficiency in breast cancer by correlating a functional phenotype with bi-allelic genotypic alterations in HR genes. Our results indicate that HR panel gene sequencing would succeed in predicting HR function with almost $90 \%$ accuracy. Lastly, our work highlights the importance of having bi-allelic alterations in the HR pathway, as opposed to 'single-hits' to result in a functional deficiency in HR. Comprehensive sequencing of HR genes may allow for a precision medicine approach for DNA damaging therapies and warrants further investigation in large cohorts from prospective clinical trials. 


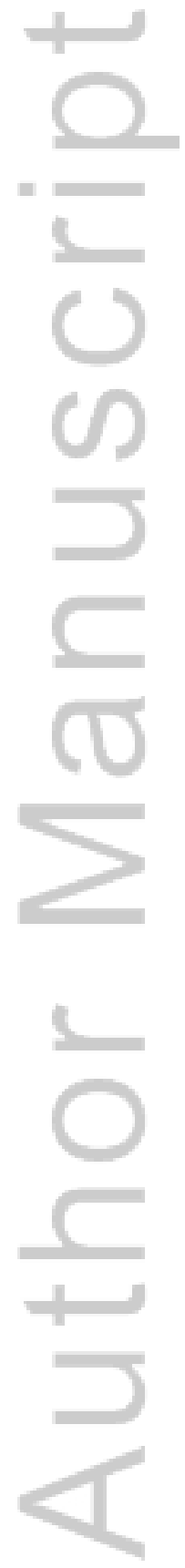

This article is protected by copyright. All rights reserved. 


\section{ACKNOWLEDGEMENTS:}

We would like to thank Mesruh Turkekul and Katia Monova for their help with immunohistochemical staining.

Funding: The sequencing core facility is supported by the Cancer Center Support Grant of the National Institutes of Health (Grant No. P30CA008748). SNP and JSR were funded in part by the Geoffrey Beene Cancer Center. SP was funded in part by a Susan G Komen Postdoctoral Fellowship Grant (PDF14298348). RWM is supported by P50 CA116201 Mayo Clinic Breast Cancer SPORE and the American Society for Radiation Oncology.

Author Contributions: S.N.P designed and conceived the study. RAD51 staining and analysis was performed by R.W.M., R.D., G.B., R.B., N.R., and S.N.P. Bioinformatics analysis and interpretation in the paper were performed by C.K.Y.N, N.R., R.S.L, P.B., A.D, W.L., B.W. and J.S.R.F. R.J provided a curated list of germline variants in DNA repair genes. M.E., M.D., D.D.G., and E.B, performed pathologic review of surgical specimens and immunohistochemical analysis. T.A.K. helped enroll patients on study and provided surgical specimens. Nucleic acid extraction and methylation analysis was performed by S.P., L.G.M., R.A.S, and B.W. The manuscript was prepared by N.R., R.M., C.K.Y.N, B.W., J.S.R.F., and S.N.P. All authors participated in the discussion and interpretation of the results.

Data and materials availability: Code used to compute LST, ntAI, HRD/LOH, and perform analysis of mutational signatures is available from the authors upon request. Sequencing data are in process of being submitted to $\mathrm{dbGaP}$ and will be available under accession to-be-determined. 


\section{REFERENCES}

1. Moynahan ME, Jasin M. Mitotic homologous recombination maintains genomic stability and suppresses tumorigenesis. Nat Rev Mol Cell Biol 2010; 11: 196-207.

2. Walsh CS. Two decades beyond BRCA1/2: Homologous recombination, hereditary cancer risk and a target for ovarian cancer therapy. Gynecol Oncol 2015.

3. $\quad$ Foulkes WD. Inherited susceptibility to common cancers. $N$ Engl J Med 2008; 359: 2143-2153.

4. Kaelin WG, Jr. The concept of synthetic lethality in the context of anticancer therapy. Nat Rev Cancer 2005; 5: 689-698.

5. Fong PC, Boss DS, Yap TA, et al. Inhibition of poly(ADP-ribose) polymerase in tumors from BRCA mutation carriers. N Engl J Med 2009; 361: 123-134.

6. Byrski T, Huzarski T, Dent R, et al. Pathologic complete response to neoadjuvant cisplatin in BRCA1-positive breast cancer patients. Breast Cancer Res Treat 2014; 147: 401-405.

7. Tutt A, Robson M, Garber JE, et al. Oral poly(ADP-ribose) polymerase inhibitor olaparib in patients with BRCA1 or BRCA2 mutations and advanced breast cancer: a proof-of-concept trial. Lancet 2010; 376: 235-244.

8. Kaufman B, Shapira-Frommer R, Schmutzler RK, et al. Olaparib monotherapy in patients with advanced cancer and a germline BRCA1/2 mutation. J Clin Oncol 2015; 33: 244-250.

9. Lord CJ, Ashworth A. BRCAness revisited. Nat Rev Cancer 2016; 16: 110-120.

10. Wessels LF, van Welsem T, Hart AA, et al. Molecular classification of breast carcinomas by comparative genomic hybridization: a specific somatic genetic profile for BRCA1 tumors. Cancer Res 2002; 62: 7110-7117.

11. Nik-Zainal S, Alexandrov LB, Wedge DC, et al. Mutational processes molding the genomes of 21 breast cancers. Cell 2012; 149: 979-993.

12. van Beers EH, van Welsem T, Wessels LF, et al. Comparative genomic hybridization profiles in human BRCA1 and BRCA2 breast tumors highlight differential sets of genomic aberrations. Cancer Res 2005; 65: 822-827.

13. Popova T, Manie E, Rieunier G, et al. Ploidy and large-scale genomic instability consistently identify basal-like breast carcinomas with BRCA1/2 inactivation. Cancer Res 2012; 72: 5454-5462.

14. Birkbak NJ, Wang ZC, Kim JY, et al. Telomeric allelic imbalance indicates defective DNA repair and sensitivity to DNA-damaging agents. Cancer Discov 2012; 2: 366-375.

15. Abkevich V, Timms KM, Hennessy BT, et al. Patterns of genomic loss of heterozygosity predict homologous recombination repair defects in epithelial ovarian cancer. Br J Cancer 2012; 107: 1776-1782.

16. Watkins JA, Irshad S, Grigoriadis A, et al. Genomic scars as biomarkers of homologous recombination deficiency and drug response in breast and ovarian cancers. Breast Cancer Res 2014; 16: 211.

17. Isakoff SJ, Mayer EL, He L, et al. TBCRC009: A Multicenter Phase II Clinical Trial of Platinum Monotherapy With Biomarker Assessment in Metastatic Triple-Negative Breast Cancer. J Clin Oncol 2015. 
18. Telli ML, Jensen KC, Vinayak S, et al. Phase II Study of Gemcitabine, Carboplatin, and Iniparib As Neoadjuvant Therapy for Triple-Negative and BRCA1/2 MutationAssociated Breast Cancer With Assessment of a Tumor-Based Measure of Genomic Instability: PrECOG 0105. J Clin Oncol 2015.

19. Graeser M, McCarthy A, Lord CJ, et al. A marker of homologous recombination predicts pathologic complete response to neoadjuvant chemotherapy in primary breast cancer. Clin Cancer Res 2010; 16: 6159-6168.

20. Willers H, Taghian AG, Luo CM, et al. Utility of DNA repair protein foci for the detection of putative BRCA1 pathway defects in breast cancer biopsies. Mol Cancer Res 2009; 7: 1304-1309.

21. Wood RD, Mitchell M, Sgouros J, et al. Human DNA repair genes. Science 2001; 291: 1284-1289.

22. Thompson LH. Recognition, signaling, and repair of DNA double-strand breaks produced by ionizing radiation in mammalian cells: the molecular choreography. Mutat Res 2012; 751: 158-246.

23. Alexandrov LB, Nik-Zainal S, Wedge DC, et al. Signatures of mutational processes in human cancer. Nature 2013; 500: 415-421.

24. Timms KM, Abkevich V, Hughes E, et al. Association of BRCA1/2 defects with genomic scores predictive of DNA damage repair deficiency among breast cancer subtypes. Breast Cancer Res 2014; 16: 475.

25. Pennington KP, Walsh T, Harrell MI, et al. Germline and somatic mutations in homologous recombination genes predict platinum response and survival in ovarian, fallopian tube, and peritoneal carcinomas. Clin Cancer Res 2014; 20: 764-775.

26. Konstantinopoulos PA, Ceccaldi R, Shapiro GI, et al. Homologous Recombination Deficiency: Exploiting the Fundamental Vulnerability of Ovarian Cancer. Cancer Discov 2015; 5: 1137-1154.

27. Gutierrez-Enriquez S, Ramon YCT, Alonso C, et al. Ionizing radiation or mitomycininduced micronuclei in lymphocytes of BRCA1 or BRCA2 mutation carriers. Breast Cancer Res Treat 2011; 127: 611-622.

28. Pierce LJ, Strawderman M, Narod SA, et al. Effect of radiotherapy after breastconserving treatment in women with breast cancer and germline BRCA1/2 mutations. J Clin Oncol 2000; 18: 3360-3369.

29. Roy R, Chun J, Powell SN. BRCA1 and BRCA2: different roles in a common pathway of genome protection. Nat Rev Cancer 2012; 12: 68-78.

30. Zhang J, Willers H, Feng Z, et al. Chk2 phosphorylation of BRCA1 regulates DNA double-strand break repair. Mol Cell Biol 2004; 24: 708-718.

31. Ceccaldi R, Sarangi P, D'Andrea AD. The Fanconi anaemia pathway: new players and new functions. Nat Rev Mol Cell Biol 2016; 17: 337-349.

32. Ochs F, Somyajit K, Altmeyer M, et al. 53BP1 fosters fidelity of homology-directed DNA repair. Nat Struct Mol Biol 2016; 23: 714-721.

33. Jiang Q, Paramasivam M, Aressy B, et al. MERIT40 cooperates with BRCA2 to resolve DNA interstrand cross-links. Genes Dev 2015; 29: 1955-1968.

34. Lord CJ, Ashworth A. Mechanisms of resistance to therapies targeting BRCA-mutant cancers. Nat Med 2013; 19: 1381-1388.

35. Tkac J, Xu G, Adhikary H, et al. HELB Is a Feedback Inhibitor of DNA End Resection. Mol Cell 2016; 61: 405-418. 
36. Zimmermann M, Lottersberger F, Buonomo SB, et al. 53BP1 regulates DSB repair using Rif1 to control 5' end resection. Science 2013; 339: 700-704.

37. Cancer Genome Atlas N. Comprehensive molecular portraits of human breast tumours. Nature 2012; 490: 61-70.

38. Ashworth A, Lord CJ, Reis-Filho JS. Genetic interactions in cancer progression and treatment. Cell 2011; 145: 30-38.

39. Couch FJ, Nathanson KL, Offit K. Two decades after BRCA: setting paradigms in personalized cancer care and prevention. Science 2014; 343: 1466-1470.

40. Mateo J, Carreira S, Sandhu S, et al. DNA-Repair Defects and Olaparib in Metastatic - Prostate Cancer. N Engl J Med 2015; 373: 1697-1708.

41. Waddell N, Pajic M, Patch AM, et al. Whole genomes redefine the mutational landscape of pancreatic cancer. Nature 2015; 518: 495-501.

42. Zhang L, Long X. Association of BRCA1 promoter methylation with sporadic breast cancers: Evidence from 40 studies. Sci Rep 2015; 5: 17869.

43. Ruscito I, Dimitrova D, Vasconcelos I, et al. BRCA1 gene promoter methylation status in high-grade serous ovarian cancer patients--a study of the tumour Bank ovarian cancer (TOC) and ovarian cancer diagnosis consortium (OVCAD). Eur J Cancer 2014; 50: 2090-2098.

44. Feng L, Fong KW, Wang J, et al. RIF1 counteracts BRCA1-mediated end resection during DNA repair. J Biol Chem 2013; 288: 11135-11143.

45. Xu G, Chapman JR, Brandsma I, et al. REV7 counteracts DNA double-strand break resection and affects PARP inhibition. Nature 2015; 521: 541-544.

46. Boersma V, Moatti N, Segura-Bayona S, et al. MAD2L2 controls DNA repair at telomeres and DNA breaks by inhibiting 5' end resection. Nature 2015; 521: 537 540.

47. Callen E, Di Virgilio M, Kruhlak MJ, et al. 53BP1 mediates productive and mutagenic DNA repair through distinct phosphoprotein interactions. Cell 2013; 153: 12661280.

48. Bolton KL, Chenevix-Trench G, Goh C, et al. Association between BRCA1 and BRCA2 mutations and survival in women with invasive epithelial ovarian cancer. JAMA 2012; 307: 382-390.

49. Asakawa H, Koizumi H, Koike A, et al. Prediction of breast cancer sensitivity to neoadjuvant chemotherapy based on status of DNA damage repair proteins. Breast Cancer Res 2010; 12: R17.

50. Willers H, Gheorghiu L, Liu Q et al. DNA Damage Response Assessments in Human Tumor Samples Provide Functional Biomarkers of Radiosensitivity. Semin Radiat Oncol 2015; 25: 237-250.

51. Panier S, Boulton SJ. Double-strand break repair: 53BP1 comes into focus. Nat Rev Mol Cell Biol 2014; 15: 7-18.

*52. Ohnishi T, Mori E, Takahashi A. DNA double-strand breaks: their production, recognition, and repair in eukaryotes. Mutat Res 2009; 669: 8-12.

*53. Geiss GK, Bumgarner RE, Birditt B, et al. Direct multiplexed measurement of gene expression with color-coded probe pairs. Nat Biotechnol 2008; 26: 317-325.

*54. Payton JE, Grieselhuber NR, Chang LW, et al. High throughput digital quantification of mRNA abundance in primary human acute myeloid leukemia samples. J Clin Invest 2009; 119: 1714-1726. 
*55. Esteller M, Silva JM, Dominguez G, et al. Promoter hypermethylation and BRCA1 inactivation in sporadic breast and ovarian tumors. J Natl Cancer Inst 2000; 92: 564569.

*56. Xu CF, Brown MA, Chambers JA, et al. Distinct transcription start sites generate two forms of BRCA1 mRNA. Hum Mol Genet 1995; 4: 2259-2264.

*57. Weinreb I, Piscuoglio S, Martelotto LG, et al. Hotspot activating PRKD1 somatic mutations in polymorphous low-grade adenocarcinomas of the salivary glands. Nat Genet 2014; 46: 1166-1169.

*58. Li H, Durbin R. Fast and accurate short read alignment with Burrows-Wheeler " transform. Bioinformatics 2009; 25: 1754-1760.

*59. DePristo MA, Banks E, Poplin R, et al. A framework for variation discovery and genotyping using next-generation DNA sequencing data. Nat Genet 2011; 43: 491498.

*60. Cibulskis K, Lawrence MS, Carter SL, et al. Sensitive detection of somatic point mutations in impure and heterogeneous cancer samples. Nat Biotechnol 2013; 31: 213-219.

*61. Koboldt DC, Zhang Q, Larson DE, et al. VarScan 2: somatic mutation and copy number alteration discovery in cancer by exome sequencing. Genome Res 2012; 22: 568-576.

*62. Saunders CT, Wong WS, Swamy S, et al. Strelka: accurate somatic small-variant calling from sequenced tumor-normal sample pairs. Bioinformatics 2012; 28: 18111817.

*63. Narzisi G, O'Rawe JA, Iossifov I, et al. Accurate de novo and transmitted indel detection in exome-capture data using microassembly. Nat Methods 2014; 11: 10331036.

*64. Thorvaldsdottir H, Robinson JT, Mesirov JP. Integrative Genomics Viewer (IGV): high-performance genomics data visualization and exploration. Brief Bioinform 2013; 14: 178-192.

*65. Yau C. OncoSNP-SEQ: a statistical approach for the identification of somatic copy number alterations from next-generation sequencing of cancer genomes. Bioinformatics 2013; 29: 2482-2484.

*66. Wang K, Li M, Hadley D, et al. PennCNV: an integrated hidden Markov model designed for high-resolution copy number variation detection in whole-genome SNP genotyping data. Genome Res 2007; 17: 1665-1674.

*67. Van Loo P, Nordgard SH, Lingjaerde OC, et al. Allele-specific copy number analysis of tumors. Proc Natl Acad Sci U S A 2010; 107: 16910-16915.

*68. Li H, Handsaker B, Wysoker A, et al. The Sequence Alignment/Map format and SAMtools. Bioinformatics 2009; 25: 2078-2079.

*69. Schultheis AM, Ng CK, De Filippo MR, et al. Massively Parallel Sequencing-Based Clonality Analysis of Synchronous Endometrioid Endometrial and Ovarian Carcinomas. J Natl Cancer Inst 2016; 108: djv427.

*70. Jiang R. Germline annotation of variants in TCGA: Available from: https://github.com/rj67/germVar2 Last Accessed ????

* References 52-70 are cited in supplementary material only 


\section{Figure Legends}

Figure 1: Schematic of study design. Tumors were prospectively collected from 56 patients for ex vivo functional assessment of the status of the HR pathway, using RAD51 foci analysis. Tumors were classified as HR deficient or proficient using this assay. A multi-faceted genomics approach, integrating whole-exome sequencing, analysis of germ-line mutations, copy number variation, gene expression, and methylation was then used to determine the underlying etiology of HRD.

Figure 2: RAD51, YH2AX, and BRCA1 nuclear foci analysis of representative RAD51proficient and RAD51-deficient case and distribution of RAD51-deficiency in breast cancer. (A) RAD51, $\mathrm{YH} 2 \mathrm{AX}$, and BRCA1 foci in a homologous recombination HR-proficient breast cancer in mock-treated (left) and irradiated conditions (right). (B) Radiation-induced RAD51, YH2AX, and BRCA1 foci in a breast tumor with deficient HR in mock-treated (left) and irradiated conditions (right). (C) Quantification of RAD51, $\mathrm{yH} 2 \mathrm{AX}$, and BRCA1 foci in cells $(n=200)$ from a tumor with proficient HR. Note strong increases in the number of cells with RAD51, YH2AX, and BRCA1 following $10 \mathrm{~Gy}$ of ionizing radiation (IR) (error bars indicate s.e.) (D.) Quantification of foci in in cells $(n=200)$ from a tumor with deficient HR. Note strong induction in $\mathrm{YH} 2 \mathrm{AX}$ with IR, without an increase in RAD51 or BRCA1 foci. All statistical comparisons were performed by comparing two proportions with a Z-test. (E) Relative fold induction of RAD51 foci formation in the irradiated, compared with the un-irradiated condition for all tumors. The relative fold induction is calculated as the number of nuclei with $>5$ foci in the irradiated state divided by the number of nuclei in the un-irradiated state. A bi-modal distribution in relative fold induction is demonstrated, with 11 tumors (black) exhibiting $<1.25$ fold induction of RAD51 foci and classified as functional HRD. $(F)$ Distribution of RAD51-deficient tumors according to the clinical subtypes of breast cancers. Although RAD51-deficiency was numerically more frequent in triple-negative breast cancers, this was not statistically significant (TNBC, $42 \%, p=0.13$, Fisher's exact test). ER, estrogen receptor; pos, positive; neg, negative.

Figure 3: Association of Genomic 'Scars' with RAD51 status (A) RAD51-deficient breast cancers harbor a higher LST score than RAD51-proficient cases $(p=0.002)$. (B) ntAl scores by 
RAD51 status in RAD51-proficient and RAD51-deficient breast cancers ( $p=0.009)$. (C) RAD51deficient breast cancers have a higher Myriad LOH/HRD score than RAD51-proficient cancers $(p=0.048)$. (D) Breast tumors with an alteration in an HR Gene (Truncating/frame-shift mutation, homozygous deletion, or non-synonymous mutation with loss-of-heterozygosity) show significantly higher LST scores than those without a genetic alteration in an HR gene $(p=$ $\left.5.2 \times 10^{-4}\right)$. Wt, wild-type. All comparisons were performed using Wilcoxon rank-sum tests.

Figure 4: Relationship between RAD51 status and gene expression and methylation. (A) Normalized NanoString expression counts of homologous recombination (HR) DNA repairrelated genes compared between DNA repair-deficient (HRD) and DNA repair-proficient tumors as determined by RAD51 foci formation. No individual gene expression was associated with RAD51 status (statistical comparisons performed with t-tests). NanoString expression counts were obtained in a subset of tumors with sufficient material $(n=20)$. Supervised hierarchical clustering was unrevealing. Bisulfite sequencing of BRCA1 promoter using primer sets for unmethylated and methylated PCR is indicated in annotation panel below RAD51 status. Note, data in figure is only shown for samples with both gene expression and methylation available, however statistical tests were performed with all available data. (B) Bisulfite sequencing of $B R C A 1$ promoter using primer sets for unmethylated and methylated PCR. The presence of a product in the methylated reaction indicates the presence of methylation in BRCA1 promoter. All bands were run on the same gel but samples re-organized during figure preparation. Vertical black lines indicate image splicing

Figure 5: Genetic changes in HR genes in RAD51-deficient and proficient samples. The repertoire of large-scale state transitions (LSTs), the number of somatic insertions and deletions (indels), association with BRCA mutational signature, as well as germline and somatic genetic alterations in genes associated with homologous recombination are presented. Cases are ordered first by RAD51 status, then by increasing LST. The number of indels for each case is divided by size according to the color key. Cases with a BRCA-associated mutation signature are annotated (see Online Methods for details). The grid illustrates the germline and somatic genetic alterations in HR genes. The types of alterations are indicated in the color key on the right. PIK3CA and TP53 mutation status, receptor and RAD51 status, are annotated in the 
phenobar (top). Exon duplication refers to a duplication of exon 3 in the BRCA2 gene. ER, estrogen receptor; TNBC, triple-negative breast cancer.

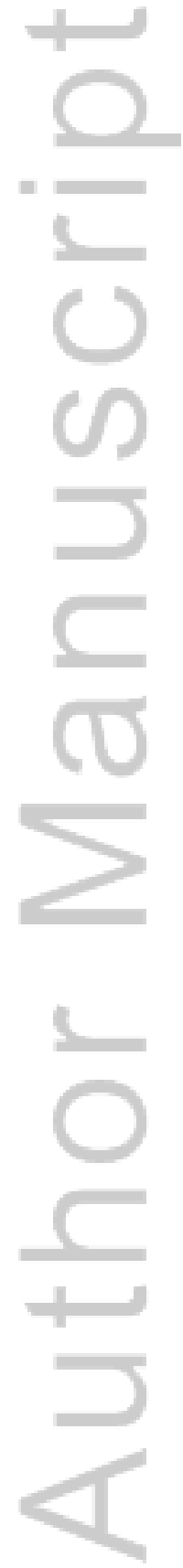

This article is protected by copyright. All rights reserved. 


\section{TABLES}

Table 1: Clinico-pathologic characteristics of breast cancer patients included in this study.

\begin{tabular}{|c|c|c|}
\hline Characteristic & No. & $\%$ \\
\hline No. of patients & 56 & \\
\hline \multicolumn{3}{|l|}{ Age, years } \\
\hline Median & 56 & \\
\hline Range & $20-81$ & \\
\hline \multicolumn{3}{|l|}{ Sex } \\
\hline Female & 55 & 98 \\
\hline Male & 1 & 2 \\
\hline \multicolumn{3}{|l|}{ Menopausal status* } \\
\hline Pre- & 25 & 45 \\
\hline Peri- & 1 & 5 \\
\hline Post- & 28 & 50 \\
\hline \multicolumn{3}{|l|}{ Family history } \\
\hline First degree & 12 & 21 \\
\hline Second degree & 15 & 27 \\
\hline \multicolumn{3}{|l|}{ Surgery } \\
\hline Mastectomy & 25 & 45 \\
\hline Lumpectomy & 31 & 55 \\
\hline ER and/or PR positive & 30 & 54 \\
\hline HER2 amplified & 14 & 25 \\
\hline Triple negative & 12 & 21 \\
\hline \multicolumn{3}{|l|}{ Tumor size } \\
\hline Median & 2.5 & \\
\hline Range & $1.1-6.5$ & \\
\hline \multicolumn{3}{|l|}{ Histologic subtype } \\
\hline Invasive ductal carcinoma & 51 & 91 \\
\hline $\begin{array}{l}\text { Invasive lobular } \\
\text { carcinoma }\end{array}$ & 5 & 9 \\
\hline \multicolumn{3}{|l|}{ Histologic Grade** } \\
\hline $1<$ & 0 & 0 \\
\hline 2 & 7 & 14 \\
\hline 3 & 44 & 86 \\
\hline \multicolumn{3}{|l|}{ Nuclear Grade ${ }^{* *}$} \\
\hline 1 & 1 & 2 \\
\hline 2 & 18 & 35 \\
\hline
\end{tabular}

This article is protected by copyright. All rights reserved. 


\begin{tabular}{|l|c|c|}
3 & 32 & 63 \\
\hline Node positive & 33 & 59 \\
\hline$\geq 4$ positive nodes & 15 & 27 \\
\hline Proliferation Index & & \\
\hline Adequate & 49 & 87.5 \\
\hline Inadequate & 7 & 12.5 \\
\hline
\end{tabular}

*1 male breast cancer patient

not included

${ }^{* *}$ Includes only invasive ductal carcinomas

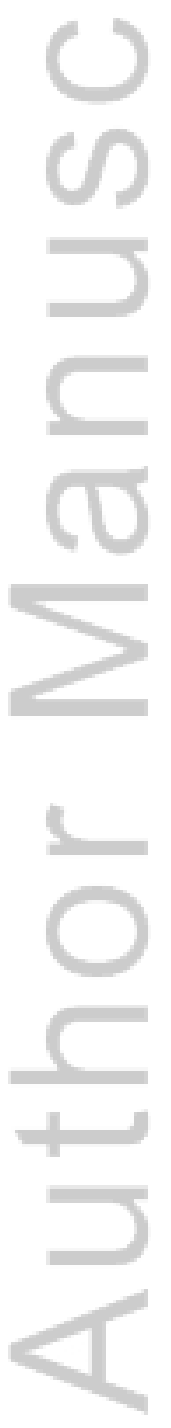

This article is protected by copyright. All rights reserved. 
Table 2: Association of clinical features with homologous repair deficiency as defined by RAD51 status. Comparisons of age and median tumor size were performed using unpaired t-test. Other statistical comparisons were performed using Fisher's exact-test.

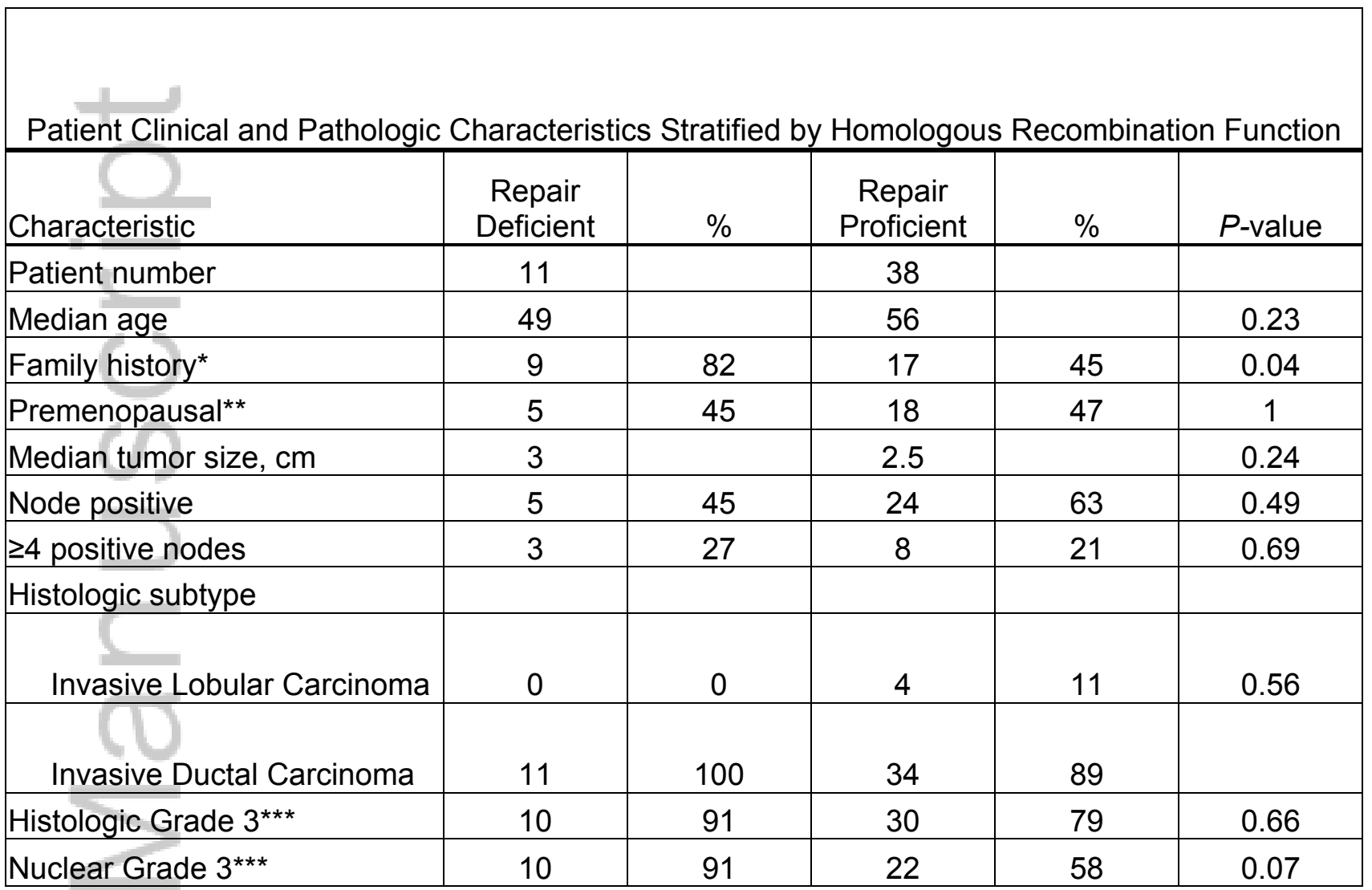

* First or Second degree

**1 male breast cancer patient excluded

${ }^{* * *}$ Includes only invasive ductal carcinomas

This article is protected by copyright. All rights reserved. 
SUPPLEMENTARY MATERIAL ONLINE

\section{Supplementary materials and methods YES}

\section{Supplementary figure legends YES}

Figure S1. Relationship between RAD51 induction and proliferation and BRCA1 induction

Figure S2. Schematic of patient enrollment in study and division of patients into HR-deficient and proficient categories

Figure S3. Copy Number calls compared to gene expression

Figure S4. Association of mono-allelic alterations in HR pathway and RAD51 deficiency and LST

Figure S5. Genetic alterations in HR pathway lead to increased LST in TCGA Breast Cancer cases

Figure S6. Recurrent mutations in breast cancer present in this cohort

Table S1. Clinical features of breast cancer patients whose tumors were subjected to whole-exome sequencing

Table S2. Summary table of exome sequencing statistics

Table S3. List of homologous recombination genes

Table S4. Table of somatic single nucleotide variants and insertions and deletions.

Table S5. Table of germline truncating and frameshift variants in HR genes.

Table S6. Table of HR genes with LOH

Table S7. BRCA1 promoter methylation primer pairs

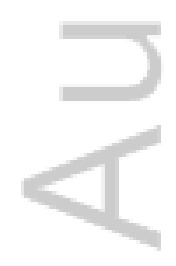

This article is protected by copyright. All rights reserved. 

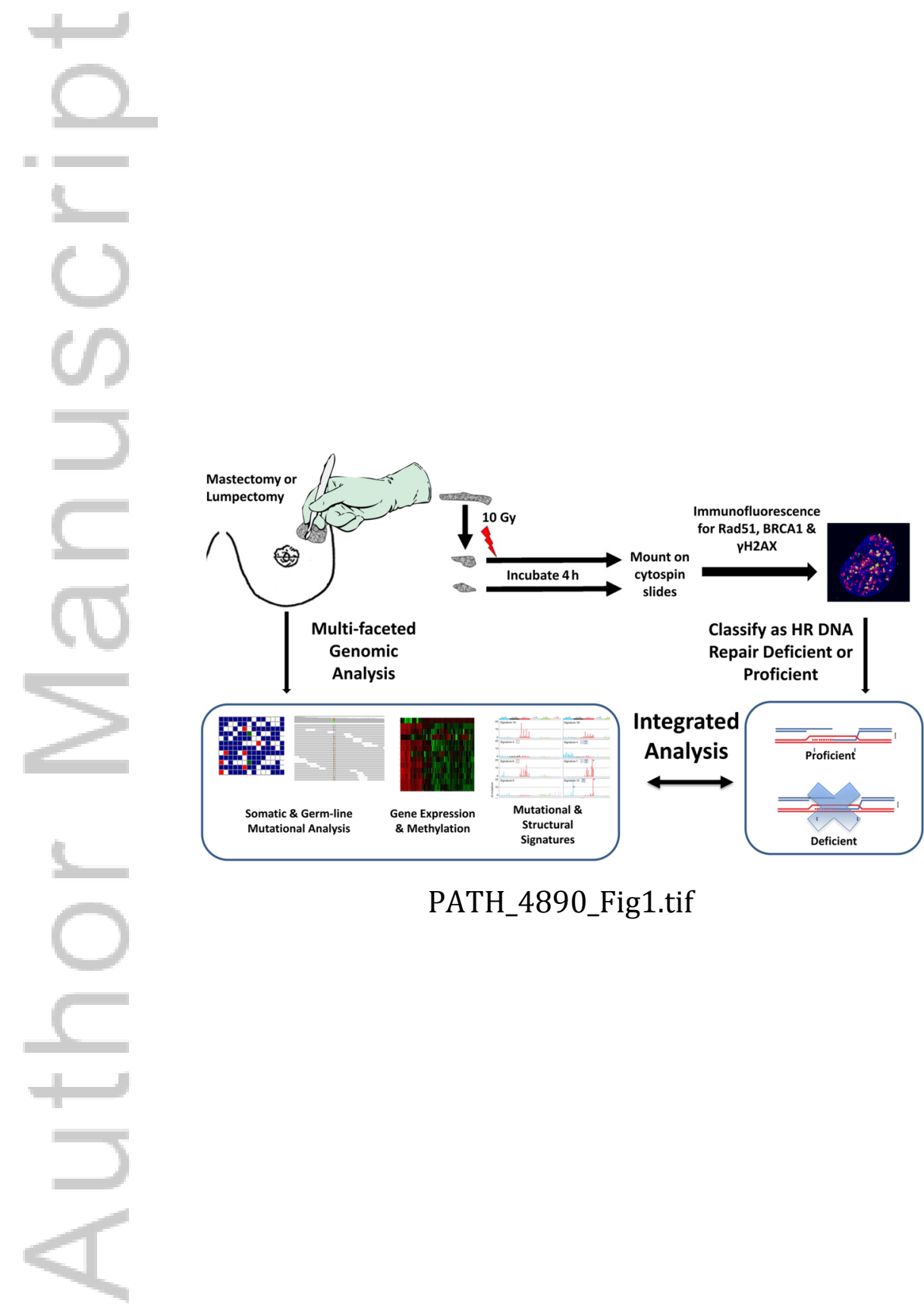

PATH_4890_Fig1.tif

This article is protected by copyright. All rights reserved. 

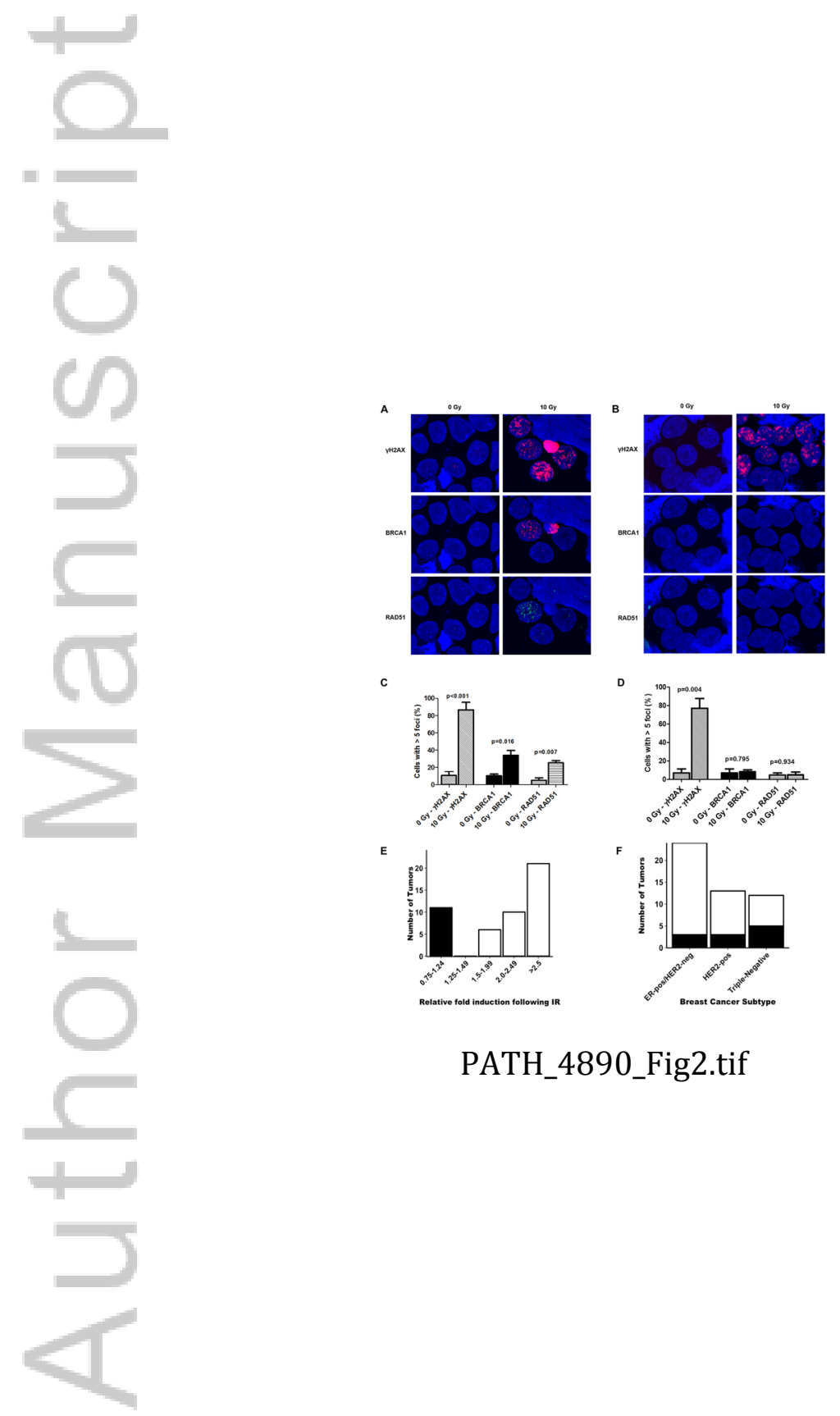

PATH_4890_Fig2.tif

This article is protected by copyright. All rights reserved. 


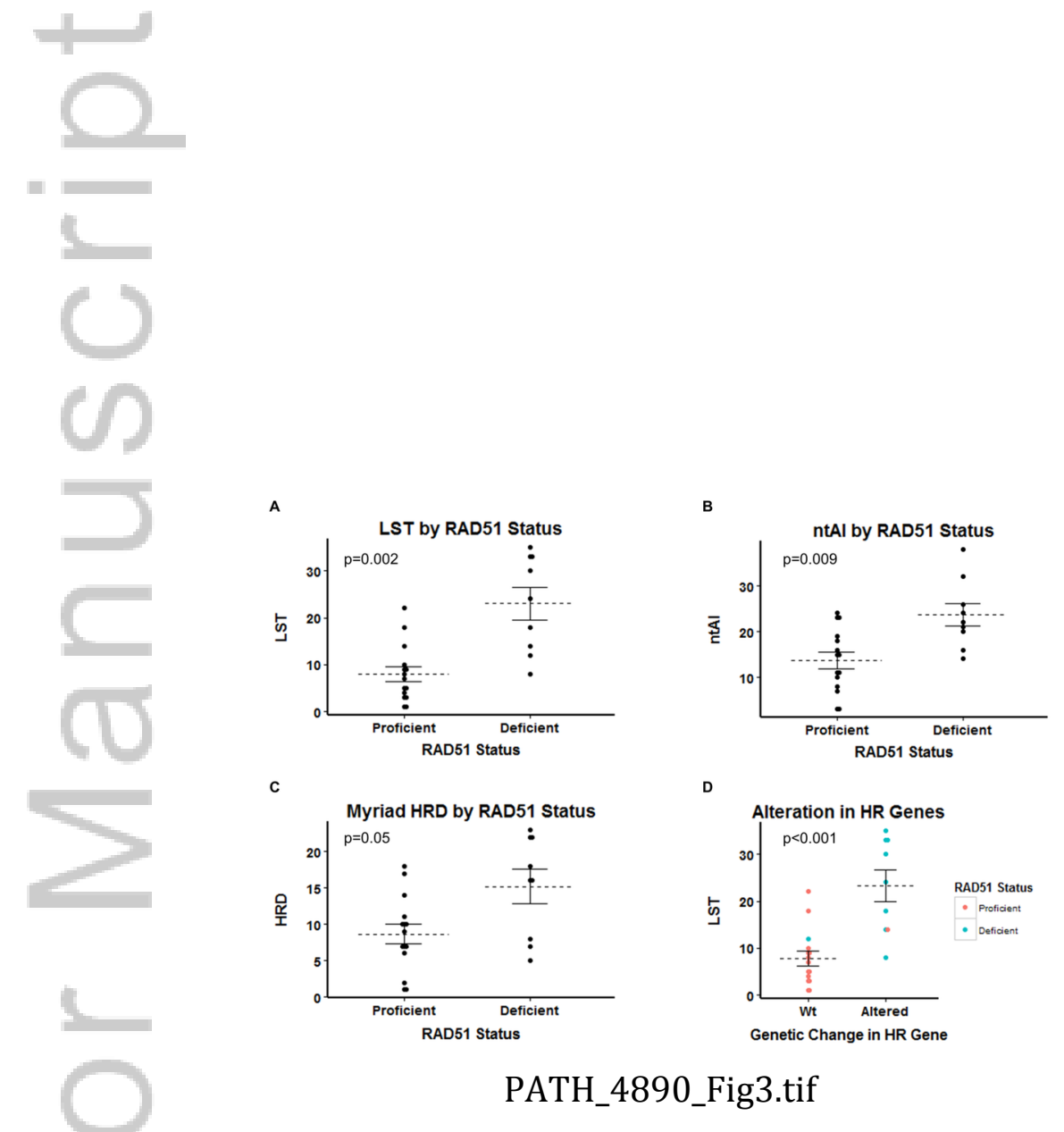

This article is protected by copyright. All rights reserved. 


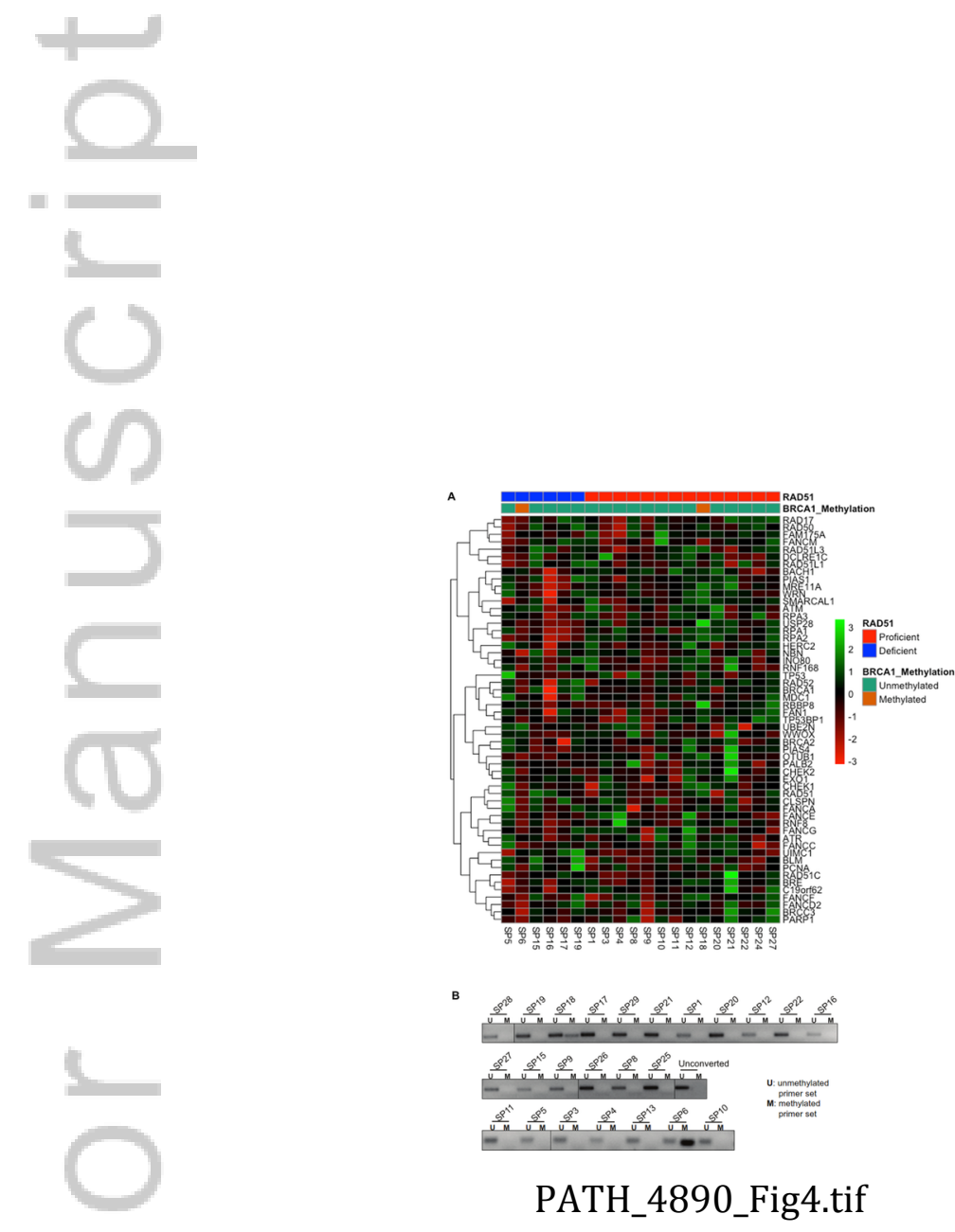

This article is protected by copyright. All rights reserved. 


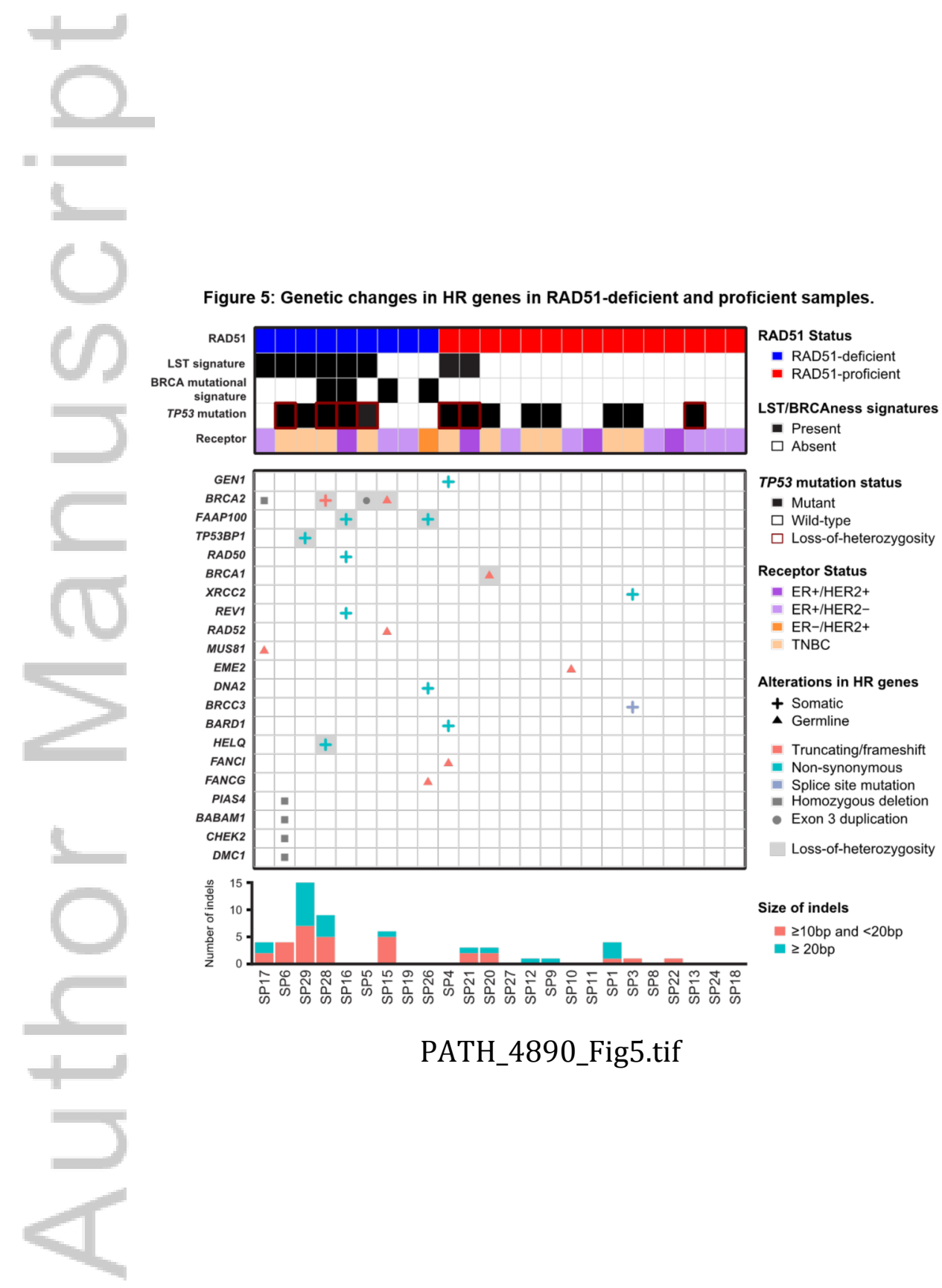

This article is protected by copyright. All rights reserved. 


\section{University Library}

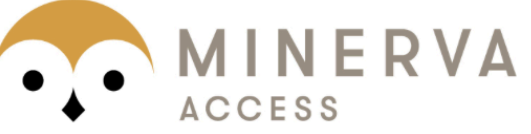

A gateway to Melbourne's research publications

Minerva Access is the Institutional Repository of The University of Melbourne

\section{Author/s:}

Mutter, RW;Riaz, N;Ng, CKY;Delsite, R;Piscuoglio, S;Edelweiss, M;Martelotto, LG;Sakr, RA;King, TA;Giri, DD;Drobnjak, M;Brogi, E;Bindra, R;Bernheim, G;Lim, RS;Blecua, P;Desrichard, A;Higginson, D;Towers, R;Jiang, R;Lee, W;Weigelt, B;Reis-Filho, JS;Powell, SN

Title:

Bi-allelic alterations in DNA repair genes underpin homologous recombination DNA repair defects in breast cancer

Date:

2017-06-01

\section{Citation:}

Mutter, R. W., Riaz, N., Ng, C. K. Y., Delsite, R., Piscuoglio, S., Edelweiss, M., Martelotto, L. G., Sakr, R. A., King, T. A., Giri, D. D., Drobnjak, M., Brogi, E., Bindra, R., Bernheim, G., Lim, R. S., Blecua, P., Desrichard, A., Higginson, D., Towers, R. ,... Powell, S. N. (2017). Bi-allelic alterations in DNA repair genes underpin homologous recombination DNA repair defects in breast cancer. JOURNAL OF PATHOLOGY, 242 (2), pp.165-177. https://doi.org/10.1002/ path.4890.

Persistent Link:

http://hdl.handle.net/11343/292822 